\title{
Optimizing Reflux Synthesis Method of Mo-V-Te-Nb mixed oxide Catalysts for
}

\section{Light Alkane Selective Oxidation}

\begin{abstract}
Amada Massó Ramírez a , Francisco Ivars-Barceló ${ }^{\text {b,* }}$, José M. López Nieto a,
a Instituto de Tecnología Química, Universitat Politècnica de València-Consejo Superior de Investigaciones Científicas, Avenida de los Naranjos s/n, 46022 Valencia, Spain.

${ }^{b}$ Dpto. de Química Inorgánica y Química Técnica, Facultad de Ciencias de la Universidad Nacional de Educación a Distancia (UNED), Paseo Senda del Rey 9, 28040 Madrid, Spain.

*E-mail:jmlopez@itq.upv.es; franciscoivars@ccia.uned.es
\end{abstract}




\section{Abstract}

This study investigates the effect of the synthesis temperature (from 80 to $110{ }^{\circ} \mathrm{C}$ ) and time (from 1 to 4 days) employed to precipitate catalyst precursors by reflux method, on the physic-chemical and the catalytic properties of the resulting Mo-V-Te-Nb mixed oxide catalysts for both propane partial oxidation into acrylic acid and ethane oxidative dehydrogenation $(\mathrm{ODH})$ to ethylene. The insight obtained has allowed an important optimization of the not commonly used reflux method to prepare Mo- $\mathrm{V}-\mathrm{Te}-\mathrm{Nb}$ oxide materials with competitive catalytic performance. The yields achieved overcome those from optimized catalysts prepared by conventional hydrothermal method, and approach those reached with catalysts prepared using "slurry method". The optimum rise for the synthesis temperature is found as a key factor for the reflux method. It allows the access to an increased vanadium content into the reflux precipitate, which favors the formation of a pseudo-amorphous Mo-V-Te-Nb oxometallate. This precipitate behaves as a precursor for the crystallization, during the solid-state activation step at high-temperature $\left(600{ }^{\circ} \mathrm{C} / \mathrm{N}_{2}\right)$, of the structure type $(\mathrm{TeO})_{2} M_{20} \mathrm{O}_{56}(M=\mathrm{Mo}, \mathrm{V}, \mathrm{Nb})$, key for the selective conversion of propane. On the other hand, for the optimum temperature of synthesis, i.e. $110{ }^{\circ} \mathrm{C}$, higher synthesis time of the precursor leads to smaller crystal sizes in the final catalyst (higher specific surface areas) and lowers the average oxidation state of vanadium from $\mathrm{V}^{+5}$ to $\mathrm{V}^{+4}$, which significantly enhances the catalytic behavior.

Keywords: light alkanes, oxidation, propane, acrylic acid, ethane, ethylene, oxidative dehydrogenation, $\mathrm{ODH}, \mathrm{Mo}-\mathrm{V}-\mathrm{Te}-\mathrm{Nb}$ oxides, reflux, M1 phase. 


\section{Introducción}

Mixed metal oxides are important catalysts in partial oxidation of hydrocarbons [1-6]. One of the more important catalytic systems developed in the last two decades are Mo$\mathrm{V}-\mathrm{Te}-\mathrm{Nb}$ mixed oxide systems, effective catalysts for light hydrocarbons partial oxidation reactions [1-7]. Especially relevant are their properties for the selective (amm)oxidation of propane into acrylic acid or acrylonitrile [8-10] and the oxidative dehydrogenation of ethane to ethylene $[11,12]$, both reactions addressed to substitute the corresponding industrial processes based on olefins currently stablished [13-15]. The use of alkane natural resources as raw materials, such as propane or ethane (present in LPG and NG), instead of olefins (produced in high energy consuming processes), intrinsically links to a more sustainable technology $[13,15]$.

The preparation of the Mo- $\mathrm{V}-\mathrm{Te}-\mathrm{Nb}$ based catalysts takes place in two separated stages: 1) synthesis of the solid precursor, and 2) precursor solid state activation at high temperature. The so called "slurry" [8-10, 16-21] and "hydrothermal" methods have been commonly employed for the synthesis of the solid precursors. Also spray-drying was proposed for preparing catalyst precursors [22-24]. However, a final activation of catalysts, a heat-treatment at $c a .600^{\circ} \mathrm{C}$ in inert atmosphere, is needed for preparing the actual catalysts $[25,26]$. Additionally, a post-synthesis purification step can improve the catalytic behavior of these catalysts [27]. Important changes in catalytic performance and nature of crystalline phases have been observed depending on the catalyst preparation methods and/or the starting materials [8-10, 16-27]. In addition, small changes in the physic-chemical characteristics of catalysts can be observed during the reaction [28]. Nevertheless, the use of the aforementioned synthesis methods has not brought significant improvements to the catalytic performance of $\mathrm{Mo}-\mathrm{V}-\mathrm{Te}-\mathrm{Nb}$ mixed oxide systems since the first works published in the 90's [8-10]. 
Despite of their advantages, those traditional methods present restrictions that could be limiting the development of materials with enhanced catalytic properties. Several years ago, it was proposed the reflux synthesis as a promising alternative method to overcome conventional methods restrictions [29]. With a reflux method, a controlled synthesis atmosphere can be stablished at temperatures above the boiling point of the solvent (feature shared by the hydrothermal method). At the same time, it is possible to interact with the system at all time, monitoring and tracking synthesis parameters (feature shared by the slurry method). Additionally, it is possible the control upon the synthesis conditions and parameters depending on the solvent volume. However, the so far reported catalysts prepared by reflux require very long synthesis times (14 days) and yet present not very competitive catalytic performance for propane selective oxidation to acrylic acid [29].

Against this backdrop, a systematic study on the effect of key parameters for the synthesis of Mo- $\mathrm{V}-\mathrm{Te}-\mathrm{Nb}$ oxides by reflux method, such as temperature and time of reflux to obtain the precursor, is conducted in this work. The successful optimization of the corresponding catalytic properties for selective oxidative transformation of propane and ethane, together with a drastic reduction of the synthesis times are presented as a result.

\section{Materials and Methods}

\subsection{Preparation of metal oxides catalysts}

Solid catalyst precursors were prepared by reflux at different temperatures $(80,100$ or $110^{\circ} \mathrm{C}$ ) and synthesis times (1, 2 or 4 days), starting from aqueous solutions mixtures of $\left(\mathrm{NH}_{4}\right)_{6} \mathrm{Mo}_{7} \mathrm{O}_{24} \cdot 4 \mathrm{H}_{2} \mathrm{O} \quad$ (Merck), $\quad \mathrm{NH}_{4} \mathrm{VO}_{3} \quad$ (Aldrich), $\quad \mathrm{Te}(\mathrm{OH})_{6} \quad$ (Aldrich), and $\left(\mathrm{NH}_{4}\right)_{2} \mathrm{Nb}_{2}\left(\mathrm{C}_{2} \mathrm{O}_{4}\right)_{5}$ (CBMM), keeping a constant molar ratio $\mathrm{Mo} / \mathrm{V} / \mathrm{Te} / \mathrm{Nb}$ of $1.00 / 0.30 / 0.16 / 0.16$ in the synthesis gel. The resulting precipitates were filtrated and 
washed with distilled water, and finally dried in air at $100{ }^{\circ} \mathrm{C}$ for $12 \mathrm{~h}$. Dried solids (precursors) were thermally activated at $600{ }^{\circ} \mathrm{C}$ for $2 \mathrm{~h}$, in a $\mathrm{N}_{2}$ stream $\left(15 \mathrm{ml} \mathrm{min}^{-1}\right.$ flow), giving rise to the final catalysts. The precursors have been named as L-t, M-t and P-t were $\mathrm{L}, \mathrm{M}$ and $\mathrm{P}$ corresponds to samples prepared at a temperature of reflux of 80,100 and $110^{\circ} \mathrm{C}$, respectively, and " $\mathrm{t}$ " refer to the time of synthesis (in days). The final catalysts, after the thermal activation treatment above described, have been named with an " $\mathrm{A}$ " at the end of the name used for their corresponding precursors.

\subsection{Characterization of solids}

The chemical analysis of the solids has been performed by inductively coupled plasma atomic emission spectrometry (ICP-AES).

The specific surface area has been determined by BET method from $\mathrm{N}_{2}$ adsorption isotherms at $77 \mathrm{~K}$ measured in a Micromeritics TriStar 3000 instrument.

X-ray diffraction (XRD) patterns of powder solids were collected with a PANalytical $C U B I X$ instrument equipped with a graphite monochromator, employing $\mathrm{Cu} \mathrm{K} \alpha$ radiation $(\lambda=0.1542 \mathrm{~mm})$ and operated at $45 \mathrm{kV}$ and $4 \mathrm{~mA}$. Distribution of crystalline phases forming the catalysts was calculated by Rietveld refinement of the XRD patterns employing $X^{\prime}$ Pert Highscore Plus software.

Solids imagery by field emission scanning electron microscopy (FESEM) was performed using a JEOL JSM 6300 LINK ISIS instrument, equipped with an energy dispersive X-ray analyzer with which chemical composition microanalyses of selected areas were implemented.

UV-vis diffuse reflectance spectroscopy measurements of the solids were carried out within the 200-800 $\mathrm{nm}$ range using a Varian spectrometer model Cary 5000. 
Temperature programed reduction analyses with $\mathrm{H}_{2}\left(\mathrm{H}_{2}-\mathrm{TPR}\right)$ were collected for the catalysts, using a Thermo Finnigan TPDRO1110 instrument equipped with a thermal conductivity detector (TCD).

Photoelectron spectra (XPS) were recorded on a SPECS spectrometer with a 150 MCD9 detector and using a nonmonochromatic $\mathrm{Al} \mathrm{K \alpha}(1486.6 \mathrm{eV}) \mathrm{X}$-ray source. Spectra were recorded using an analyzer pass energy of $30 \mathrm{~V}$, an X-ray power of $100 \mathrm{~W}$, and an operating pressure of $5 \times 10^{-10}$ Torr. Spectral treatment was performed using the CASA software. Binding energies (BE) were referenced to the $\mathrm{C} 1 \mathrm{~s}$ peak at $284.5 \mathrm{eV}$.

\subsection{Catalytic Studies}

A fixed-bed tubular quartz reactor was utilized to study the catalytic properties of the different Mo-V-Te-Nb oxide catalysts $[11,19]$. The catalytic tests in both partial oxidation of propane and oxidative dehydrogenation of ethane were performed within the temperature range of $340-440{ }^{\circ} \mathrm{C}$. A particle size range of $0.3-0.5 \mathrm{~mm}$ was stablished for the catalysts during the catalytic tests, the mass of which was varied to obtain catalytic results at different contact times. The reaction feed consisted in a mixture of $\mathrm{C}_{3} \mathrm{H}_{8} / \mathrm{O}_{2} / \mathrm{H}_{2} \mathrm{O} / \mathrm{He}$ with $4 / 8 / 30 / 58$ molar ratio (propane oxidation), or $\mathrm{C}_{2} \mathrm{H}_{6} / \mathrm{O}_{2} / \mathrm{He}$ with a molar ratio of 9/7/84 (for ethane $\mathrm{ODH}$ ), employing a total flow of $50 \mathrm{ml} \mathrm{min}{ }^{-1}$. Reactants and products were analyzed online employing a gas chromatograph equipped with two

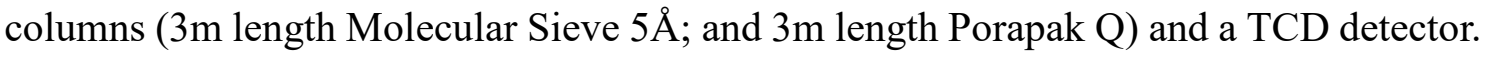
As the amount of sample employed largely varies depending on the experiment, the catalysts have been diluted with silicon carbide to keep a constant volume for the catalytic bed. 


\section{Results and Discussion}

\section{$\underline{\text { 3.1. Study of Catalyst Precursors }}$}

Powder XRD patterns of the precipitates obtained by reflux at different temperatures ( 80 , 100 or $110^{\circ} \mathrm{C}$ ) and synthesis times (1, 2 or 4 days) appear very similar (Figure 1 ), with broad and low intensity peaks indicative of solids with low atomic periodicity. All XRD patterns display bands centered at $2 \theta$ angles of 22 and $28^{\circ}$, which appear as main diffractions in some molybdates with perovskite-type derived structures [23, 30]. Diffraction peak at $2 \theta=22^{\circ}$ corresponds to the typical $4 \AA$ distance between consecutive [001] planes of Mo cations in oxygen octahedral coordination [17]. On the other hand, although differences among diffraction patterns of precipitates as a function of temperature and/or time of reflux synthesis are not significantly appreciated, the presence of a small low angle peak $\left(2 \theta=8^{\circ}\right)$ seems to be slightly favored at increasing synthesis times and lower temperatures. This low angle peak has been observed in Keggin-type structure polyoxomolybdates with $\mathrm{NH}_{4}{ }^{+}, \mathrm{H}^{+}$and/or $\mathrm{K}^{+}$compensation cations [31-33]. The diffraction peak at $2 \theta=28^{\circ}$ has been also observed in polyoxometalate structures [34].

Notwithstanding the XRD similarities among the reflux precipitates, significant differences are observed in their chemical composition (Table 1) as a function of synthesis time and especially of reflux temperature. Thus, the maximum variation is observed when comparing $\mathrm{V} / \mathrm{Mo}$ and Te/Mo molar ratios between precipitates obtained at the lowest and highest temperature, i.e. at 80 and $110^{\circ} \mathrm{C}$. With respect to the changes in $\mathrm{V}$ and $\mathrm{Te}$ contents as a function of time, they are especially relevant at $80^{\circ} \mathrm{C}$, gradually becoming less significant as increasing the reflux temperature. In general, variations in the $\mathrm{Nb} / \mathrm{Mo}$ molar ratio are less significant. 
For the reflux precipitates prepared at $80^{\circ} \mathrm{C}$, the content in both $\mathrm{V}$ and Te appears favored with the synthesis time, while the $\mathrm{Nb}$ slightly decreases. Concretely, the V/Mo molar ratio in the reflux precipitates is almost doubled (from 0.6 to 0.11 ) and that of Te/Mo increased more than $30 \%$ (from 0.16 to 0.21 ) as going from 24 to $96 \mathrm{~h}$ of synthesis at $80{ }^{\circ} \mathrm{C}$. Contrarily, the $\mathrm{Nb} / \mathrm{Mo}$ molar ratio decreases ca. $20 \%$ from 24 to $48 \mathrm{~h}$ remaining relatively constant at higher synthesis time.

The incorporation of either $\mathrm{V}$ or $\mathrm{Te}$ in the reflux precipitate appears favored as increasing the reflux temperature as well, although the dependence with the synthesis time at the set temperature is gradually vanishing. Thus, in contrast with the precipitates at $80{ }^{\circ} \mathrm{C}$, extending the synthesis times at $110^{\circ} \mathrm{C}$ induced no significant correlation nor variation of $\mathrm{V} / \mathrm{Mo}$ or Te/Mo molar ratios in the resulting precipitate (Table 1). Nevertheless, moving from 80 to $110{ }^{\circ} \mathrm{C}$ for the same synthesis time of 1 day, leads to $c a .60 \%$ increment in the Te/Mo molar ratio and triples that of $\mathrm{V} / \mathrm{Mo}$ in the resulting precipitate. Regardless of the synthesis time, Te/Mo and especially V/Mo values in $110{ }^{\circ} \mathrm{C}$ precipitates are not even achieved with the longest synthesis times at $80{ }^{\circ} \mathrm{C}$.

These changes in the chemical composition among solids precipitated by reflux at different temperature and synthesis time (table 1) are reflected in relevant morphology variations. Thus, two differentiated morphologies are present in precursors with $\mathrm{V} / \mathrm{Mo}$ molar ratio bellow 0.16: i) micrometer-scale rod-shape crystals, and ii) amorphous-like conglomerate formed by aggregated nanometer-scale clusters. As a case in point, a FESEM micrography of the precipitate for 4 days at $80{ }^{\circ} \mathrm{C}$ (sample L-4) is displayed in Figure 2. On the other hand, only amorphous aggregates are observed in precursors with V/Mo molar ratio $\geq 0.16$, where crystalline rod-shape particles are hardly found, as shown eg. in FESEM micrographies of M-4 and P-4 samples (Figure 2). 
The study of the chemical composition by EDAX of selected areas in FESEM micrographies, reveals a common enrichment of vanadium in all amorphous aggregates (average V/Mo molar ratio of 0.17 ), regardless of the reflux temperature, compared with the crystalline rod-shape structures where vanadium is absent or hardly present (average V/Mo molar ratio of 0.05 ). With respect to the Te/Mo molar ratio, it remains equivalent between both morphologies, with variable values within the $0.16-0.21$ range. Nevertheless, a marked tendency for higher $\mathrm{Nb}$ content is found in the V-rich amorphous particles $(0.24$ average $\mathrm{Nb} / \mathrm{Mo}$ molar ratio) compared with the rod-shape long crystals which are poor in vanadium $(0.17$ average $\mathrm{Nb} / \mathrm{Mo}$ molar ratio).

\subsection{Characterization of Catalysts}

The actual samples used as catalysts for propane partial oxidation reaction, which will be discussed later, result from the thermal activation treatment $\left(600^{\circ} \mathrm{C} / 2 \mathrm{~h}\right.$ in $\mathrm{N}_{2}$ stream $)$ of the precipitates by reflux. In contrast with the low crystallinity observed by XRD for the precursors (Figure 1), their thermal activation give rise to the formation of well-defined crystalline phases (Figure 3). The distributions of solid phases, calculated by Rietveld refinement from the catalysts XRD patterns, are displayed in Table 1. The L-1A catalyst, derived from the lowest both reflux temperature and synthesis time, mainly contain crystalline phases type $M_{5} \mathrm{O}_{14}(45 \%)$ [JCPDS: $31-1437$ ] and $\mathrm{Te} M_{5} \mathrm{O}_{16}(18 \%)$ [JCPDS: 31 0874], as well as a significant amount of amorphous solid (38\%). This catalyst presents no trace of $(\mathrm{TeO})_{2} \mathrm{M}_{20} \mathrm{O}_{56}$ structure [JCPDS: 18-582], the so-called M1 phase, directly related with the selective conversion of the alkane [10,11, 16-29]. As increasing the time used to prepare the precursor at $80{ }^{\circ} \mathrm{C}$ reflux, the content in $\mathrm{Te}_{5} \mathrm{O}_{16}$ structure grows up and the M1 phase starts gradually emerging in the resulting catalysts (samples L-2A and 
L-4A), while $M_{5} \mathrm{O}_{14}$ and especially amorphous solids recede (Table 1). Moving the reflux temperature from 80 to $100{ }^{\circ} \mathrm{C}$, at equivalent synthesis times, also enhances the content of M1 phase in the final activated catalysts, even more drastically than extending the synthesis time. Thus, the precursor precipitated for 1 day reflux synthesis at $100{ }^{\circ} \mathrm{C}$ leads to a final activated catalyst (sample M-1A) with M1 phase amount slightly above that for the catalyst derived from 4 times longer synthesis at $80{ }^{\circ} \mathrm{C}$ (sample L-1A). Something similar occurs with the $110{ }^{\circ} \mathrm{C}$ synthesis, where the catalyst derived from the shortest reflux time (sample P-1A) equals and doubles the M1 phase content of catalysts from 4 times longer synthesis at 100 and $80{ }^{\circ} \mathrm{C}$, respectively. However, for the case of $110{ }^{\circ} \mathrm{C}$ precursor synthesis, the time-dependent effect on the M1 phase amount in the resulting activated catalyst (increments $\leq 5 \%$ ) is not so strong than for 80 and $100{ }^{\circ} \mathrm{C}$ syntheses. On the other hand, no $\mathrm{Te}_{0.33} \mathrm{MO}_{3.33}$ (the so-called $\mathrm{M} 2$ phase: $M=\mathrm{Mo}, \mathrm{V}, \mathrm{Nb}$ ) has been observed in these catalysts, regardless of the synthesis conditions. In this way, we must indicate that this phase is usually observed in Mo-V-Te-Nb-O catalysts prepared by coprecipitation $[10,16-18]$, but not frequent when the catalysts are hydrothermally prepared $[16,19-21]$.

Heat-treated samples of L- and M-series (i.e. samples prepared at 80 and $100^{\circ} \mathrm{C}$, respectively) are characterized by the presence of Raman bands at ca. 936, 860, 796, 459, 340 and $240 \mathrm{~cm}^{-1}$ with shoulders at 684 and $994 \mathrm{~cm}^{-1}$ (figure 4). Bands at, 936, 860, and $684 \mathrm{~cm}^{-1}$ have been attributed to $M_{5} \mathrm{O}_{14}$ crystallites (with $M=\mathrm{Mo}, \mathrm{V}, \mathrm{W}$ ) $[35,36]$. The shoulder at ca. $990 \mathrm{~cm}^{-1}$ can be assigned to stretching vibrations of terminal $\mathrm{Mo}=\mathrm{O}$ and $\mathrm{V}=\mathrm{O}$ bonds [37]. In the case of $\mathrm{P}$-series catalysts, especially that from 4 days precursor precipitation (P-4A), the Raman spectra show the main presence of bands at 872 and 478 $\mathrm{cm}^{-1}$ (also observed as minority in M-series catalysts) which have been related to M1 phase [38]. In this way, it has been proposed that in the case of M1 phase, the bands at 
$770-880 \mathrm{~cm}^{-1}$ appear in a typical regime of asymmetric cation-O-cation bridge stretching modes, while the low frequency band (at $c a .470 \mathrm{~cm}^{-1}$ ) appear in a typical regime of the symmetric one [38]. Raman spectra confirm the XRD results, with a low information about the nature of non-crystalline phases, although these are minority in the case of catalysts mainly presenting M1 phase (i.e. P-4A).

Comparing the results from chemical composition analyses of the precursors and the distribution of phases in the catalysts, a direct relation is found between the incorporation of vanadium in the precursor and the formation of M1 phase upon thermal activation. The Figure 5 displays a linear correlation between the percentage of M1 phase present in the catalysts and the V/Mo molar ratio present in the corresponding precursor, with a limit apparently stablished from $0.16 \mathrm{~V} / \mathrm{Mo}$ values. At this point, it should be reminded that $\mathrm{V}$ incorporation in the precursor (Table 1), favored for longer synthesis time and especially for higher reflux temperature, was preferentially observed (EDAX-FESEM) in the amorphous-like aggregates. Accordingly, the higher the V/Mo molar ratio in the precursor the higher the presence of amorphous-like conglomerate observed by FESEM, compared with the V-free rod-shape crystals (Figure 2). A maximum is reached for the highest V/Mo values $\geq 0.16$, where long rod-shape crystals cannot be found by FESEM.

Although it is coherent the buffered growth of M1 phase in the catalysts derived from 110 ${ }^{\circ} \mathrm{C}$ precursors whose V/Mo molar ratios (within 0.16-0.17) are not gradually increasing, the correlation in Figure 5 does not explain the even small but significant increment of the cited active phase in these samples. Instead, XPS results of these catalysts from Pseries (i.e. those derived from $110^{\circ} \mathrm{C}$ synthesis) seem to shed some light on the issue (Table 2), since the synthesis time for the reflux synthesis at $110{ }^{\circ} \mathrm{C}$ shows to have an important effect on the electronic configuration of the elements near the surface of the resulting catalyst. The most relevant effect is observed for vanadium. Thus, a minority +4 
oxidation state $\left(16 \% \mathrm{~V}^{+4}\right)$ in the $\mathrm{P}-1$ catalyst, derived from 1 day reflux precipitate, is drastically inverted as increasing the precursor synthesis time, to become the major oxidation state in the catalysts derived from 2 days and 4 days reflux precipitates, with $64 \%$ and $83 \% \mathrm{~V}^{+4}$, respectively. Regarding the $\mathrm{Te}$ and $\mathrm{Nb}$ near surface in the catalysts derived from $110^{\circ} \mathrm{C}$ reflux precipitates, they mainly appear as $\mathrm{Te}^{+4}$ and $\mathrm{Nb}^{+5}$. Both elements undergo definitive stabilization in their respective electronic configurations near surface of the catalyst from the $48 \mathrm{~h}$ reflux synthesis (P-2A catalyst). Thus, the mixed valence $\mathrm{Te}^{+4}$ and $\mathrm{Te}^{+6}$ present in the $\mathrm{P}-1 \mathrm{~A}$ catalyst is completely reduced to $\mathrm{Te}^{+4}$ in the $\mathrm{P}$ 2A catalyst, while the initial $\mathrm{Nb}^{3+}$ and $\mathrm{Nb}^{5+}$ mixture is totally oxidized (Table 2).

In Table 2 are shown also some redox features determined for the catalysts derived from precursors prepared at $110{ }^{\circ} \mathrm{C}$ (P-series). Redox potentials were calculated from the corresponding band gap energy, i.e. the energy needed to promote an electron from the valence band into the conduction band. The band gap energies have been obtained from the diffuse reflectance UV-vis spectra of the catalyst, representing the Kubelka-Munk equation as a function of the UV-vis adsorption energy measured, and extrapolating to the intersection point with the "x" axis where the given function is zero (Figure 6) [10]. Thus, redox potentials determined for the catalysts derived from $110^{\circ} \mathrm{C}$ precursors are lower as increasing the synthesis time of the precursor, i.e. the catalyst is more reduced, so that it has less tendency to be reduced and therefore less oxidant character. This trend is confirmed by the results from temperature-programmed reduction with $\mathrm{H}_{2}\left(\mathrm{H}_{2}-\mathrm{TPR}\right)$ of the catalysts $\mathrm{P}-1, \mathrm{P}-2$ and $\mathrm{P}-4$, which present increasing temperature for the maximum of reduction, i.e. 504, 514 and $527^{\circ} \mathrm{C}$, respectively (Table 2, and Fig. S1 in supplementary information).

The lower oxidation state of the vanadium observed by XPS of the materials of P-series (Table 2) by increasing the time of synthesis of the precipitate is in good agreement with 
the redox potentials (Table 2, Fig. 5) and the results of $\mathrm{H}_{2}$-TPR (Table 2, Fig. S1 in supplementary information).

On the other hand, higher reflux temperatures and longer synthesis times give rise to final catalysts with proportionally increased surface areas (Table 1). Although in general the areas are low, it is quite significant the gradual increment as increasing either temperature or time for the precursor precipitation by reflux synthesis (Table 1). Thus, the catalyst surface area is doubled as extending the synthesis time from 1 day to 4 days to prepare the precursor at $110{ }^{\circ} \mathrm{C}(\mathrm{P}$-series). Accordingly, FESEM micrographies of these catalysts (Fig. S2 in supplementary information) show the averaged crystal size is significantly reduced in the catalyst derived from the precursor prepared at 4 days (P-4 catalyst), which confirms the reliability of the surface area results, at least in relative terms.

\subsection{Catalytic tests for propane oxidation and ethane oxidative dehydrogenation}

The catalytic properties of these materials have been studied for the selective oxidation of propane to acrylic acid and for the oxidative dehydrogenation (ODH) of ethane within the $340-420^{\circ} \mathrm{C}$ temperature range.

For propane partial oxidation, acrylic acid, propylene, acetic acid and carbon oxides are the main oxidation products (sum $\geq 97 \%$ of total products). Acrylic acid appears as the main reaction product at alkane conversions above $20 \%$, in all cases. On the contrary, lower propane conversions favor the production of propylene, as corresponds to its primary product condition. Acetic acid and $\mathrm{CO}_{\mathrm{x}}$, products involving $\mathrm{C}-\mathrm{C}$ bond breaks, are more favored as the alkane conversion increases [14-21, 24].

The main catalytic results for propane partial oxidation are summarized in the Figure 7, which comparatively displays propane conversion and yield of acrylic acid for the most 
representative catalysts. In general, enhancements of both catalytic activity (propane conversion) and yield of acrylic acid are observed as increasing the reflux temperature and synthesis time employed to precipitate the catalyst precursor. In the case of the catalysts derived from $80{ }^{\circ} \mathrm{C}$ reflux precipitates (with minority active phase, M1) the catalytic activity observed is very low $(<10 \%)$, while the catalysts from $110{ }^{\circ} \mathrm{C}$ reflux precipitates (with the richest M1 phase contents) show the highest propane conversions and acrylic acid yields.

Therefore, the improvement in the propane selective conversion into acrylic acid over catalysts prepared at increased temperature and time of the precursor reflux synthesis is relatively well explained with the M1 active phase enrichment of the catalysts. Nevertheless, the strong enhancement of either alkane conversion or acrylic acid yield as extending the synthesis time for $110 \mathrm{C}$ reflux precipitates, appears not proportional to the small M1 phase increments (Table 1) in these catalysts. However, the gradual increased specific area (up to $>100 \%$ ) along with the progressive drop in the redox potential (up to ca.50\%), as moving from 1 to 4 days precursor synthesis, do appear to properly correlate with the doubled conversion and yield out coming.

In the case of ethane $\mathrm{ODH}$ the main results are summarized in Figure 8. Ethylene, carbon monoxide, and carbon dioxide were observed only as reaction products, with a carbon balance of $c a .100 \%$. In addition, all catalysts presented a selectivity to ethylene higher than $95 \%$ at conversion of ethane lower than $30 \%$, which agrees with previous catalytic results on $\mathrm{Mo}-\mathrm{V}-\mathrm{Te}-\mathrm{Nb}-\mathrm{O}$ mixed oxides reported on catalysts prepared hydrothermally $[10,11,22]$ or by co-precipitation $[38,39]$. In this way, the presence of crystalline phases such as $M_{5} \mathrm{O}_{14}$ or $\mathrm{Te} M_{5} \mathrm{O}_{16}(M=\mathrm{Mo}, \mathrm{V}, \mathrm{Nb})$ has no influence in both ethylene formation or ethylene combustion [38]. On the other hand, a parallelism between the propane partial oxidation and the ethane ODH is also observed, in agreement to previous results $[38,39]$, 
indicating the key role of M1 phase in activity and selectivity during both propane and ethane oxidation.

\section{Conclusions}

A new synthesis method, based in reflux precipitation, is presented for developing complex Mo-V-Te-Nb mixed oxide catalysts. From the study about the effect of temperature and time for the synthesis of the catalyst precursor by reflux precipitation, a direct correlation can be stablished between the vanadium incorporation into the solid and the incremented temperature for the synthesis of the catalyst precursor. Vanadium appears selectively incorporated into amorphous-like aggregates, favoring their formation versus rod-shape crystals as increasing the vanadium content in the reflux precipitate. The higher the V/Mo molar ratio in these precursors the larger the amount of M1 active phase in the resulting activated catalyst.

Although vanadium incorporation into the reflux precipitate is also induced with longer synthesis time, the access to certain V/Mo molar ratios appears strictly conditioned by the reflux temperature. Thus, temperatures of synthesis higher than $100{ }^{\circ} \mathrm{C}$ are needed to obtain precursors with high enough V/Mo molar ratios leading to a major formation of M1 active phase $(>60 \%)$ in the final catalysts.

The largest amount of M1 active phase has been obtained for an optimum reflux temperature of $110{ }^{\circ} \mathrm{C}$. Longer synthesis times at $110{ }^{\circ} \mathrm{C}$ give rise to smaller crystal sizes in the final catalysts (higher surface area) and lower redox potentials mainly due to the reduction of $\mathrm{V}^{+5}$ to $\mathrm{V}^{+4}$, which together result in a significant improvement of the catalytic properties for the propane selective oxidation into acrylic acid. The optimum results have been achieved with the P-4A catalyst (i.e. with precursor synthesis carried out at $110{ }^{\circ} \mathrm{C}$ 
and 4 days), showing selectivity to acrylic acid above $75 \%$ within the $20-50 \%$ range of propane conversion at $400^{\circ} \mathrm{C}$. In the same way, the optimum results for ethane $\mathrm{ODH}$ was achieved on the same catalyst, showing a selectivity to ethylene above 95 within the 20 50 range of ethane conversion at $400^{\circ} \mathrm{C}$. Additionally, in both cases there is a parallelism between the amount of M1 phase and the yield to acrylic acid (from propane) and to ethylene (from ethane).

\section{Acknowledgements}

Authors gratefully acknowledge the funds from DGICYT by the project CTQ201568951-C3-1-R, as well as the funds from Comunidad de Madrid by the project 2017T1/IND-6025 within the program “Atracción y Retención de Talento Investigador” of the V PRICIT.

\section{References}

[1] R.K. Grasselli, J.D. Burrington, D.J. Buttrey, P. DeSanto, C.G. Lugmair, A.F. Volpe, T. Weingand, Top. Catal., 23 (2003) 5-22.

[2] A. Chieregato, J.M. López Nieto, F. Cavani, Coord. Chem. Rev. 301-302 (2015) 323.

[3] J.C. Védrine, I. Fechete, Heterogeneous partial oxidation catalysis on metal oxides, Compt. Rend. Chim. 19 (2016) 1203-1225.

[4] J.M. Lopez Nieto, B. Solsona, Gas phase heterogeneous partial oxidation reactions, in: J.C. Vedrine (Ed.) Metal Oxides in Heterogeneous Catalysis, Elsevier, 2018, pp. 211-286.

[5] C. Sprung, G.S. Yablonsky, R. Schlögl, A. Trunschke, Catalysts, 8 (2018) 1-32.

[6] R.K. Grasselli,, Catal. Today 238 (2014) 10-27.

[7] J.M. López Nieto, B. Solsona, P. Concepcion, F. Ivars, A. Dejoz, M.I. Vazquez, Catal. Today, 157 (2010) 291-296.

[8] T. Ushikubo, H. Nakamura, Y. Koyasu, S. Wajiki, Method for producing an unsaturated carboxylic acid, US Patent 5,380,933,(1995), assigned to Mitsubushi Kasei Corporation, 1995.

[9] T. Ushikubo, K. Oshima, A. Kayou, M. Hatano, Stud. Surf. Sci. Catal. 112 (1997) 473-480. 
[10] H. Tsuji, Y. Koyasu, J. Am. Chem. Soc. 124 (2002) 5608-5609.

[11] P. Botella, E. Garcia-Gonzalez, A. Dejoz, J.M. López Nieto, M.I. Vazquez, J. Gonzalez-Calbet, J. Catal. 225 (2004) 428-438.

[12] a) J.M. López Nieto, P. Botella, M.I. Vázquez, A. Dejoz, Method for the oxidative dehydrogenation of ethane, US Patent 7,319,179 B2 (2008); b) J.M. López Nieto, P. Botella, M.I. Vázquez, A. Dejoz, Method for the oxidative dehydrogenation of ethane, EP 1,479,438 A1 (2004), assigned to CSIC and UPV.

[13] J.L. Dubois, Catal. Today 99 (2005) 5-14.

[14] J.-L.P. Dubois, S. Gregory, J.M.M Millet, Propane-selective Oxidation to Acrylic Acid, in: M.V.d.V. Bert Sels (Ed.) Nanotechnology in Catalysis: Applications in the Chemical Industry, Energy Development, and Environment Protection, Wiley-VCH, 2017, pp. 503-535.

[15] A.M. Gaffney, O.M. Mason, Catal. Today 285 (2017) 159-165.

[16] P. Botella, E. García-González, J.M. López Nieto, J.M. González-Calbet, Solid State Sci. 7 (2005) 507-519.

[17] A. Celaya Sanfiz, T.W. Hansen, A. Sakthivel, A. Trunschke, R. Schlogl, A. Knoester, H.H. Brongersma, M.H. Looi, S.B.A. Hamid, J. Catal. 258 (2008) 35-43.

[18] T.T. Nguyen, B. Deniau, M. Baca, J.-M.M. Millet, Top. Catal. 59 (2016) 1496-1505.

[19] P. Botella, J.M. López Nieto, B. Solsona, A. Mifsud, F. Marquez, J. Catal. 209 (2002) 445-455.

[20] D. Vitry, Y. Morikawa, J.L. Dubois, W. Ueda, Appl. Catal. A: Gen 251 (2003) 411424.

[21] A. Celaya Sanfiz, T.W. Hansen, F. Girgsdies, O. Timpe, E. Rodel, T. Ressler, A. Trunschke, R. Schlogl, Top. Catal. 50 (2008) 19-32.

[22] P. Beato, A. Blume, F. Girgsdies, R.E. Jentoft, R. Schlogl, O. Timpe, A. Trunschke, G. Weinberg, Q. Basher, F.A. Hamid, S.B.A. Hamid, E. Omar, L.M. Salim, Appl. Catal. A: Gen 307 (2006) 137-147.

[23] H. Hibst, F. Rosowski, G. Cox, Catal. Today 117 (2006) 234-241.

[24] A. Celaya Sanfiz, T.W. Hansen, D. Teschner, P. Schnoerch, F. Girgsdies, A. Trunschke, R. Schloegl, M.H. Looi, S.B.A. Hamid, J. Phys. Chem. C 114 (2010) 1912-1921.

[25] T.Y. Kardash, E.V. Lazareva, D.A. Svintsitskiy, A.V. Ishchenko, V.M. Bondareva, R.B. Neder, RSC Adv. 8 (2018) 35903-35916.

[26] P. Concepcion, S. Hernandez, J.M.Lopez Nieto, Appl. Catal. A: Gen 391 (2011) 92101.

[27] M. Baca, J.M.M. Millet, Appl. Catal. A: Gen 279 (2005) 67-77.

[28] S. Lwin, W. Diao, C. Baroi, A.M. Gaffney, R.R. Fushimi, Catalysts, 7 (2017) 109.

[29] I. Ramli, P. Botella, F. Ivars, W. Pei Meng, S.M.M. Zawawi, H.A. Ahangar, S. Hernández, J.M.L. Nieto, J. Mol. Catal. A: Chem. 342-343 (2011) 50-57.

[30] P. Botella, A. Dejoz, J.M. López Nieto, P. Concepción, M.I. Vázquez, Appl. Catal. A: Gen 298 (2006) 16-23. 
[31] H. D'Amour, R. Allmann, Z. Kristall. - Cryst. Mat. 1976, pp. 1.

[32] A. Leclaire, M.M. Borel, J. Chardon, B. Raveau, Mat. R. Bull. 30 (1995) 1075-1080.

[33] M.N. Corella-Ochoa, H.N. Miras, A. Kidd, D.-L. Long, L. Cronin, Chem. Commun. 47 (2011) 8799-8801.

[34] P. Botella, J.M. López Nieto, B. Solsona, Catal. Lett. 78 (2002) 383-387.

[35] G. Mestl, J. Raman Spect. 33 (2002) 333-347.

[36] M. Dieterle, G. Mestl, Phys. Chem. Chem. Phys. 4 (2002) 822-826.

[37] H. Knoezinger, H. Jeziorowski, J. Phys. Chem. 82 (1978) 2002-2005.

[38] B. Solsona, M.I. Vázquez, F. Ivars, A. Dejoz, P. Concepción, J.M. López Nieto, J. Catal. 252 (2007) 271-280.

[39] T.T. Nguyen, L. Burel, D.L. Nguyen, C. Pham-Huu, J.M.M. Millet, Appl. Catal. A: Gen. 433-434 (2012) 41-48. 
Table 1. Synthesis conditions and chemical composition of the reflux precipitates and characteristics of catalysts.

\begin{tabular}{|c|c|c|c|c|c|c|c|c|c|c|}
\hline \multicolumn{5}{|c|}{ Precursors } & \multicolumn{6}{|c|}{ Heat-treated samples (catalysts) } \\
\hline \multirow[t]{2}{*}{ Sample } & \multirow{2}{*}{$\begin{array}{l}\text { Synthesis } \\
\text { Conditions }\end{array}$} & \multicolumn{3}{|c|}{ Composition (ICP) ${ }^{a}$} & \multirow[t]{2}{*}{ Sample } & \multirow{2}{*}{$\begin{array}{l}\text { Surface } \\
\text { area } \\
\left(\mathrm{m}^{2} \mathrm{~g}^{-1}\right)\end{array}$} & \multicolumn{4}{|c|}{ XRD results } \\
\hline & & V/Mo & $\mathrm{Te} / \mathrm{Mo}$ & $\mathrm{Nb} / \mathrm{Mo}$ & & & M1 phase & $M_{5} \mathrm{O}_{14}$ & $\mathrm{Te} M_{5} \mathrm{O}_{16}$ & N.C. \\
\hline L-1 & $80^{\circ} \mathrm{C} / 1$ day & 0.06 & 0.16 & 0.27 & L-1A & 0.1 & $<1$ & 45 & 18 & 38 \\
\hline L-2 & $80^{\circ} \mathrm{C} / 2$ days & 0.08 & 0.20 & 0.23 & L-2A & 0.7 & 15 & 21 & 36 & 27 \\
\hline L-4 & $80^{\circ} \mathrm{C} / 4$ days & 0.11 & 0.21 & 0.22 & L-4A & 1.4 & 32 & 20 & 39 & 9 \\
\hline M-1 & $100^{\circ} \mathrm{C} / 1$ day & 0.13 & 0.23 & 0.27 & M-1A & 0.8 & 38 & 39 & 10 & 12 \\
\hline M-2 & $100^{\circ} \mathrm{C} / 2$ days & 0.14 & 0.24 & 0.26 & M-2A & 2.5 & 55 & 24 & 8 & 13 \\
\hline M-4 & $100^{\circ} \mathrm{C} / 4$ days & 0.16 & 0.26 & 0.28 & M-4A & 4.2 & 64 & 20 & 6 & 11 \\
\hline P-1 & $110^{\circ} \mathrm{C} / 1$ day & 0.17 & 0.25 & 0.29 & P-1A & 2.0 & 64 & 18 & 4 & 14 \\
\hline P-2 & $110^{\circ} \mathrm{C} / 2$ days & 0.16 & 0.25 & 0.27 & P-2A & 3.6 & 69 & 7 & 4 & 20 \\
\hline P-4 & $110^{\circ} \mathrm{C} / 4$ days & 0.17 & 0.22 & 0.24 & P-4A & 4.6 & 73 & 3 & 5 & 19 \\
\hline
\end{tabular}

a) Chemical composition of solid precursors measured by AES-ICP and expressed as molar ratio normalized with respect to Mo content.

b) $\%$ of amorphous (N.C.) and crystalline phases: $M_{5} \mathrm{O}_{14}(M=\mathrm{Mo}, \mathrm{V}, \mathrm{Nb})$ [JCPDS: 31-1437]; $\mathrm{Te}_{5} \mathrm{O}_{16}(M=\mathrm{Mo}, \mathrm{V}, \mathrm{Nb})$ [JCPDS: 31-0874]; M1 phase: $(\mathrm{TeO})_{2} M_{20} \mathrm{O}_{56}(M=\mathrm{Mo}, \mathrm{V}, \mathrm{Nb})$ [JCPDS: 18-582]; determined by Rietveld refinement from XRD patterns. 
Table 2. XPS results and redox properties of catalysts derived from $110^{\circ} \mathrm{C}$ reflux precipitates (P-series) at different synthesis time.

\begin{tabular}{|c|c|c|c|c|c|c|c|}
\hline \multirow[t]{2}{*}{ Catalyst } & \multirow{2}{*}{$\begin{array}{l}\text { XPS } \\
\text { Mo/V/Te/Nb }{ }^{a}\end{array}$} & \multicolumn{3}{|c|}{$\mathbf{M}^{\mathrm{cat}} / \mathbf{M T}_{\mathrm{T}}(\mathrm{XPS})^{\mathrm{b}}$} & \multicolumn{2}{|c|}{ DRS-UV-vis } & \multirow{2}{*}{$\begin{array}{l}\mathrm{H}_{2} \text {-TPR } \\
\text { T }_{\text {red }} \\
\left({ }^{\circ} \mathrm{C}\right)^{\mathrm{e}}\end{array}$} \\
\hline & & $\mathbf{V}^{+4}$ & $\mathrm{Te}^{+4}$ & $\mathbf{N b}^{+5}$ & $\begin{array}{l}\text { Egap } \\
(\mathrm{eV})^{\mathrm{c}}\end{array}$ & $\begin{array}{l}\text { Pred } \\
(1 / \mathrm{eV})^{\mathbf{d}}\end{array}$ & \\
\hline L-1A & $1 / 0.09 / 0.38 / 0.29$ & 0.16 & 0.73 & 0.67 & 1.1 & 0.91 & 504 \\
\hline L-2A & $1 / 0.10 / 0.32 / 0.28$ & 0.64 & 1 & 1 & 1.2 & 0.83 & 514 \\
\hline L-4A & $1 / 0.09 / 0.36 / 0.26$ & 0.83 & 1 & 1 & 1.9 & 0.53 & 527 \\
\hline
\end{tabular}

a) Atomic ratio; ${ }^{\text {b) }} \boldsymbol{M}^{\text {cat }} / \boldsymbol{M}_{T}$, atomic ratio between the specific metal cation and the total amount of the element in all the oxidation states found: $\mathrm{V}(\mathrm{V})+\mathrm{V}(\mathrm{IV}), \mathrm{Te}(\mathrm{VI})+\mathrm{Te}(\mathrm{IV})$ and $\mathrm{Nb}(\mathrm{V})+\mathrm{Nb}(\mathrm{III}){ }^{\mathrm{c}} \mathrm{E}_{\text {gap }}$, Band gap energy value taken as the intersection point with the $\mathrm{x}$-axis (absorption energy) of the Kubelka-Munk function for a null value of the given function $[\mathrm{F}(\mathrm{R} \infty) \mathrm{h} v]^{1 / 2}=0$; Kubelka-Munk equation represented as function of the absorption energy measured in diffuse reflectance UV-vis spectrum in Fig. 6 ; ${ }^{\text {d) }} \mathrm{P}_{\text {red, }}$, redox potential, inverse of the band gap energy; ${ }^{\text {e) }} \mathrm{T}_{\text {red, }}$, temperature at the maximum of the $\mathrm{H}_{2}$-TPR curve. 


\section{Caption to figures}

Fig. 1. Powder XRD patterns of precipitates obtained by reflux at temperatures of 80 (Lseries), 100 (M-series) or $110^{\circ} \mathrm{C}$ (P-series), and time of synthesis of 1,2 or 4 days.

Fig. 2. FESEM images of reflux precipitates obtained by 4 days reflux synthesis at: 80 ${ }^{\circ} \mathrm{C}$ (sample L-4), $100{ }^{\circ} \mathrm{C}$ (sample M-4) or $110{ }^{\circ} \mathrm{C}$ (sample P-4).

Fig. 3. XRD patterns of the catalysts $\left(600{ }^{\circ} \mathrm{C} / \mathrm{N}_{2}\right.$ treatment $)$ derived from precursors precipitated by reflux at different temperatures $\left(80^{\circ} \mathrm{C}\right.$, L-series; $100^{\circ} \mathrm{C}, \mathrm{M}$-series; $110{ }^{\circ} \mathrm{C}, \mathrm{P}$-series) and synthesis time (1, 2 or 4 days). Key to symbols for the majority phases present: (o) $M_{5} \mathrm{O}_{14}$ [JCPDS: 31-1437], ( $\mathbf{\Delta}$ ) TeM5 $\mathrm{O}_{16}$ [JCPDS: 310874], (*) (TeO) ${ }_{2} M_{20} \mathrm{O}_{56}$ [JCPDS: 18-582]; (M: Mo, V, Nb).

Fig. 4: Raman spectra of heat-treated catalysts: i) L-series (prepared at $80^{\circ} \mathrm{C}$ ) with synthesis time of: 1 day (L-1) and 4 days (L-4); ii) M-series (prepared at $100^{\circ} \mathrm{C}$ ) with synthesis time of: 1 day (M-1), 2 days (M-2), and 4 days (M-4); iii) P-series (prepared at $110^{\circ} \mathrm{C}$ ) with synthesis time of: 1 day (P-1); 2 days (P-2); and 4 days (P-4).

Fig. 5. Correlation between the V/Mo molar ratio measured by ICP-AES in reflux precipitates (catalyst precursors) and the content of $(\mathrm{TeO})_{2} M_{20} \mathrm{O}_{56}$ structure $(M=$ Mo, V, Nb) [JCPDS: 18-582], the so-called M1 phase, in the final activated catalysts (determined by Rietveld refinement of XRD patterns).

Fig. 6. Kubelka-Munk equation $[\mathrm{F}(\mathrm{R} \infty) \mathrm{h} v]^{1 / 2}$ as function of the absorption energy measured in the diffuse reflectance UV-vis spectra of the catalysts obtained from precursors precipitated by reflux at $110^{\circ} \mathrm{C}$ for 1,2 or 4 days (catalysts P-1A, P2A and P-4A, respectively).

Fig. 7. Propane conversion and yield of acrylic acid of the catalysts derived from precipitates at different reflux temperature and synthesis time. Reaction conditions for propane partial oxidation: Temperature $=380{ }^{\circ} \mathrm{C}$; contact time, $\mathrm{W} / \mathrm{F}=814 \mathrm{~g}_{\text {cat }}$ $\mathrm{h}^{-1}\left(\mathrm{~mol}_{\mathrm{C} 3 \mathrm{H} 8}\right)^{-1}$.

Fig. 8. Ethane conversion and yield to ethylene of the catalysts derived from precipitates at different reflux temperature and synthesis time. Reaction conditions for ethane $\mathrm{ODH}$ : Temperature $=440{ }^{\circ} \mathrm{C}$; contact time, $\mathrm{W} / \mathrm{F}=156 \mathrm{~g}_{\mathrm{cat}} \mathrm{h}^{-1}\left(\operatorname{mol}_{\mathrm{C} 3 \mathrm{H} 8}\right)^{-1}$. 